\title{
KONTRIBUSI KECERDASAN EMOSIONAL TERHADAP KOMUNIKASI INTERPERSONAL DALAM PEMBELAJARAN MATEMATIKA
}

\author{
Nurul Fitri Hidayah, Fitrah Amelia, Hermansah* \\ Program Studi Pendidikan Matematika, Fakultas Keguruan dan Ilmu Pendidikan \\ Universitas Riau Kepulauan, Batam, Kepulauan Riau \\ e-mail: "bankhermansah@gmail.com
}

\begin{abstract}
Abstrak. Penelitian ini dilatarbelakangi oleh rendahnya nilai siswa, rendahnya kerja tim, kurang meratanya siswa yang mencapai pemahaman materi yang disebabkan oleh kurangnya inisiatif dan rasa percaya diri siswa dalam memulai komunikasi. Penelitian ini dilakukan untuk mengetahui : (1) Hubungan positif antara kecerdasan emosional terhadap komunikasi interpersonal dalam pembelajaran matematika siswa kelas VII SMP Negeri 26 Batam tahun pelajaran 2015/2016, (2) Besar kontribusi kecerdasan emosional terhadap komunikasi interpersonal dalam pembelajaran matematika siswa kelas VII SMP Negeri 26 Batam tahun pelajaran 2015/2016. Jenis penelitian ini yaitu penelitian korelasi dengan pendekatan kuantitatif dengan jumlah populasi yaitu 313 siswa. Pengambilan sampel dilakukan dengan probability sampling, yaitu simple random sampling dan ukuran sampel ditentukan dengan rumus Slovin, yaitu minimal 177 siswa. Jenis instrumen untuk kecerdasan emosional dan komunikasi interpersonal, yaitu kuesioner tertutup. Kemudian teknik analisis instrumen menggunakan uji validitas berupa validitas isi dan validitas konstruksi (korelasi Product Moment dari Karl Pearson). Sedangkan uji reliabilitas menggunakan teknik Alpha Cronbach. Peneliti melakukan analisis data menggunakan uji normalitas berupa uji Kolmogorov-Smirnov dan uji hipotesis menggunakan korelasi Pearson Product Moment, uji signifikansi, dan rumus koefisien determinan. Hasil penelitian, menunjukkan : (1) Terdapat hubungan positif yang signifikan antara kecerdasan emosional terhadap komunikasi interpersonal dalam pembelajaran matematika siswa kelas VII SMP Negeri 26 Batam yang tergolong cukup kuat. (2) Terdapat kontribusi antara kecerdasan emosional terhadap komunikasi interpersonal dalam pembelajaran matematika siswa kelas VII SMP Negeri 26 Batam sebesar 29,57\%. Sedangkan sisanya sebesar 70,43\% dipengaruhi oleh faktor-faktor lain diluar penelitian ini.
\end{abstract}

Kata kunci: kecerdasan emosional, komunikasi interpersonal, pendidikan, matematika

Abstract. This research is motivated by low student value, low team work, unevenness of students who reach material understanding caused by lack of initiative and confidence of student in starting communication. This research was conducted to know: (1) Positive relationship between emotional intelligence to interpersonal communication in learning mathematics of VII students of SMP Negeri 26 Batam in academic year 2015/2016, (2) Great contribution of emotional intelligence to interpersonal communication in learning mathematics of VII students of SMP Country 26 Batam lesson year 2015/2016. The type of this research is correlation research with quantitative approach with total population of 313 students. Sampling is done by probability sampling, that is simple random sampling and sample size determined by Slovin formula, that is minimum 177 students. Instrument type for emotional intelligence and interpersonal communication, ie closed questionnaire. Then the instrument analysis technique using validity test of content validity and construction validity (Product Moment correlation from Karl Pearson). While the reliability test using Cronbach Alpha technique. The researcher conducted data analysis using normality test in the form of Kolmogorov-Smirnov test and hypothesis test using Pearson Product Moment correlation, significance test, and determinant coefficient formula. The result of the research shows: (1) There is a significant positive correlation between emotional intelligence to interpersonal communication in learning mathematics of VII students of SMP Negeri 26 Batam which is quite strong. (2) There is contribution between emotional intelligence to interpersonal communication in 
learning mathematics of student of class VII of SMP Negeri 26 Batam equal to 29,57\%. While the rest of $70,43 \%$ influenced by other factors outside this research.

Keyword: emotional intelligence, interpersonal communication, education, mathematics

\section{Pendahuluan}

Pendidikan merupakan salah satu media dalam mendapatkan ilmu pengetahuan. Dengan ilmu pengetahuan maka seseorang dapat mengembangkan kualitas diri, kualitas hidup, potensi diri, serta keterampilan diri. Untuk menunjang kualitas pendidikan formal, pemerintah telah melakukan pengembangan kurikulum yaitu kurikulum 2013. Pada kurikulum 2013 ini tidak hanya memusatkan kecerdasan intelektual (IQ) saja, tetapi juga kecerdasan emosional dan kecerdasan spiritual (SQ). Selain itu, kurikulum 2013 juga menggunakan pendekatan saintifik dan model - model pembelajaran kooperatif, dimana di dalam pendekatan saintifik ini siswa dituntut untuk belajar mandiri dalam memahami materi pembelajaran. Sedangkan model pembelajaran kooperatif ini dibutuhkan kerjasama tim, yaitu berupa interaksi sosial yang tentunya dimulai dengan adanya kontak dan komunikasi untuk mencapai tujuan pembelajaran mandiri.

Berdasarkan hasil pengamatan peneliti pada saat melakukan program pengalaman lapangan (PPL) di SMP Negeri 26 Batam, pembelajaran menggunakan kurikulum 2013 agak sulit bagi siswa. Karena pelajaran matematika berkaitan dengan pelajaran berhitung yang sangat membutuhkan pola pikir dan logika. Sedangkan kemampuan pola pikir dan logika masingmasing siswa tentunya berbeda. Namun, masih terdapat kurang meratanya siswa yang mencapai pemahaman materi serta masih terlihat rendahnya kerja tim, dimana dalam kerja kelompok hanya dikerjakan oleh siswa yang sudah memahami materi.

Hal ini disebabkan oleh kurangnya inisiatif dan rasa percaya diri siswa dalam memulai komunikasi untuk bertanya kepada teman yang sudah memahami materi. Padahal dengan inisiatif dan rasa percaya diri, siswa akan terdorong untuk memulai komunikasi. Dengan memulai komunikasi, maka akan terjadi interaksi. Dengan interaksi, akan membangun kerja tim siswa dalam suatu kelompok belajar. Dengan interaksi juga, siswa saling membantu dalam memahami materi pembelajaran. Hal ini tentunya akan berdampak positif bagi siswa dalam memperoleh hasil belajar, baik secara personal maupun secara berkelompok.

Menurut Goleman (Goleman, 2016) , setinggi-tingginya IQ menyumbang kira-kira 20\% bagi faktor-faktor yang menentukan sukses dalam hidup, jadi yang $80 \%$ diisi oleh kekuatankekuatan lain. Sedangkan (Nggermanto, 2015) memaparkan bahwa setidaknya sekitar 75\% kesuksesan manusia lebih ditentukan oleh kecerdasan emosionalnya (EQ) dan hanya 4\% yang ditentukan oleh IQ - nya. Di dalam kecerdasan emosional ada beberapa kerangka kerja menurut Daniel Goleman (Nggermanto, 2015), kerangka kerja ini terdiri dari lima kategori utama yaitu : kesadaran diri, pengaturan diri, motivasi, empati, dan keterampilan sosial. Berdasarkan kerangka kerja yang disebutkan oleh Goleman, dapat disimpulkan bahwa komunikasi merupakan bagian dari kecerdasan emosional. Karena dengan kemampuan seseorang mengelola emosinya, maka akan berdampak positif terhadap komunikasinya. 
Emosi menurut Feldman (Suciati, 2015), merupakan perasaan yang memiliki elemen fisiologis dan kognitif serta memengaruhi perilaku. Emosi memiliki sisi positif dan negatif, namun itu tergantung pada pribadi seseorang dalam mengarahkan serta meluapkannya. Sehingga untuk memaksimalkan dan mengarahkan emosi itu sendiri dibutuhkan kemampuan mental yang disebut kecerdasan emosional.

Lingkungan sekolah merupakan salah satu tempat yang sangat sering terjadinya komunikasi. Dance (Rakhmat, 2011) mengartikan komunikasi dalam kerangka psikologi behaviorisme sebagai usaha "menimbulkan respons melalui lambang-lambang verbal" ketika lambang-lambang verbal tersebut bertindak sebagai stimuli. Salah satu pelaku komunikasi yaitu siswa dengan siswa lainnya. Jika terjadi komunikasi antara siswa dengan siswa lainnya atau siswa dengan beberapa siswa lainnya, maka komunikasi itu disebut komunikasi interpersonal.

Menurut Effendy (Edward, 2015), komunikasi antar pribadi adalah komunikasi antara seorang komunikator dengan seorang komunikan. Komunikasi ini dianggap paling efektif dalam upaya mengubah sikap, pendapat atau perilaku seseorang, karena sifatnya dialogis berupa percakapan. Berdasarkan landasan teori di atas, peneliti menyimpulkan bahwa setiap komunikasi pastinya berkaitan dengan emosi. Emosilah yang mendorong individu untuk melakukan komunikasi. Tanpa emosi mungkin tidak akan terjadi komunikasi. Namun, jika emosi tersebut merupakan emosi negatif maka itu akan berdampak buruk terhadap komunikasi interpersonal. dan sebaliknya, jika emosi tersebut merupakan emosi positif maka itu akan berdampak baik terhadap komunikasi interpersonal. Sehingga, peneliti perlu meneliti apakah kecerdasan emosional berkontribusi terhadap komunikasi interpersonal dalam pembelajaran siswa SMP Negeri 26 Batam.

\section{Metode Penelitian}

Jenis penelitian yang digunakan dalam penelitian ini adalah penelitian korelasi dengan pendekatan kuantitatif. Penelitian ini diarahkan untuk melihat kontribusi dari kecerdasan emosional $(X)$ terhadap komunikasi interpersonal $(Y)$ dalam pembelajaran matematika siswa kelas VII SMP Negeri 26 Batam tahun pelajaran 2015/2016.

Penelitian ini dilaksanakan di SMP Negeri 26 Batam tahun 2016 dari tanggal 7 Agustus sampai dengan 29 Agustus 2016. SMP Negeri 26 Batam terletak di Jl. Rindang Garden-Batu Aji, Batam. Populasi pada penelitian ini adalah seluruh siswa-siswi kelas VII SMP Negeri 26 Batam angkatan 2015/2016 sebanyak 313 siswa. Untuk menentukan sampel pada penelitian ini, penulis menggunakan teknik probability sampling, yaitu simple random sampling (Siregar, 2015: 57). Kemudian, untuk menentukan ukuran sampel peneliti menggunakan rumus Slovin sehingga diperoleh minimal sampel yaitu 177 siswa. Dan peneliti menetapkan sebanyak 184 siswa yang digunakan sebagai sampel dalam penelitian ini.

Instrumen yang digunakan untuk pengumpulan data kecerdasan emosional dan komunikasi interpersonal adalah angket atau kuesioner tertutup. Sedangkan untuk menganalisis instrumen 
penelitian ini, peneliti menggunakan uji validitas isi dan uji validitas konstruksi yaitu Product Moment dari Karl Pearson sebesar 0,544. Serta uji reliabilitas, yaitu teknik Alpha Cronbach.

Secara manual peneliti melakukan uji prasyarat menggunakan uji normalitas dengan metode Kolmogorov-Smirnov dan uji hipotesis dengan korelasi Pearson Product Moment, uji signifikansi, dan koefisien determinasi.

\section{Hasil Penelitian dan Pembahasan}

Berdasarkan data kecerdasan emosional dan data komunikasi interpersonal siswa kelas VII tahun pelajaran 2015/2016, diperoleh hasil sebagai berikut:

Tabel 1. Uji Normalitas Kecerdasan Emosional dan Komunikasi Interpersonal

\begin{tabular}{|c|c|c|c|}
\hline \multicolumn{2}{|c|}{ Uji } & \multicolumn{2}{|c|}{ Normalitas } \\
\hline \multirow{2}{*}{ Nilai Max } & D1 & 0,0699 & 0,0606 \\
\hline & D2 & 0,0527 & 0,0605 \\
\hline \multicolumn{2}{|c|}{$\mathrm{N}$} & 184 & 184 \\
\hline \multicolumn{2}{|c|}{ Std } & 7,2115 & 6,1991 \\
\hline \multicolumn{2}{|c|}{ Dhitung } & 0,0699 & 0,0606 \\
\hline \multicolumn{2}{|c|}{ Dtabel } & 0,0995 & 0,0995 \\
\hline \multicolumn{2}{|c|}{ Hipotesis } & Dhit $\leq$ Dtabel & Dhit $\leq$ Dtabel \\
\hline \multicolumn{2}{|c|}{ Keputusan } & Ho diterima & Ho diterima \\
\hline
\end{tabular}

Berdasarkan hasil uji normalitas diatas, artinya data kecerdasan emosional dan data komunikasi interpersonal siswa kelas VII tahun pelajaran 2015/2016 berdistribusi secara normal. Setelah data berdistribusi secara normal, peneliti melanjutkan analisis data uji hipotesis pada penelitian ini menggunakan korelasi Pearson Product Moment (Riduwan; \& Sunarto, 2011) Dan perhitungan uji hipotesis dilakukan secara manual, yaitu sebagai berikut :

$$
\begin{aligned}
r_{X Y} & =\frac{n(\Sigma X Y)-(\Sigma X) \cdot(\Sigma Y)}{\sqrt{\left[n \cdot \Sigma X^{2}-(\Sigma X)^{2}\right] \cdot\left[n \cdot \Sigma Y^{2}-(\Sigma Y)^{2}\right]}} \\
& =\frac{184 \times(1241198)-(16114) \times(14122)}{\sqrt{[(184 \times 1420718)-(16114)] \times\left[(184 \times 1090896)-(14122)^{2}\right]}} \\
& =\frac{228380432-227561908}{\sqrt{1751116 \times 1293980}}=\frac{818524}{1505293,686} \\
& =0,544
\end{aligned}
$$

Berdasarkan hasil uji hipotesis di atas, diperoleh nilai $r_{x y}=0,544$ dengan ketegori cukup kuat. Artinya kecerdasan emosional memiliki hubungan yang cukup kuat terhadap komunikasi 
interpersonal. Pengujian lanjutan yaitu uji signifikansi yang berfungsi untuk mencari makna hubungan variabel X terhadap Y, maka hasil korelasi Pearson Product Moment tersebut diuji dengan uji signifikansi secara manual sebagai berikut:

$$
\begin{aligned}
t_{\text {hitung }} & =\frac{r \sqrt{n-2}}{\sqrt{1-r^{2}}} \\
& =\frac{0,544 \sqrt{184-2}}{\sqrt{1-(0,544)^{2}}} \\
& =\frac{0,544 \times 13,49}{\sqrt{1-0,296}} \\
& =\frac{7,34}{0,839}=8,749
\end{aligned}
$$

Sehingga diperoleh nilai uji $\mathrm{t}_{\text {hitung }}=8,749 \geq \mathrm{t}_{\text {tabel }}=0,674$ dengan keputusan $\mathrm{H}_{0}$ ditolak. Artinya terdapat hubungan positif yang signifikan antara kecerdasan emosional terhadap komunikasi interpersonal dalam pembelajaran matematika siswa kelas VII SMP Negeri 26 Batam Tahun Pelajaran 2015/2016. Untuk mengetahui seberapa besar kontribusinya, maka peneliti melakukan perhitungan menggunakan koefisien determinan. Hasil perhitungan manual, yaitu sebagai berikut:

$$
\begin{aligned}
K P & =r^{2} \times 100 \% \\
& =(0,544)^{2} \times 100 \% \\
& =0,2957 \times 100 \% \\
& =29,57 \%
\end{aligned}
$$

Berdasarkan hasil pengujian hipotesis diketahui bahwa terdapat hubungan positif yang signifikan antara variabel bebas dan variabel terikat. Variabel bebas pada penelitian ini yaitu kecerdasan emosional dan variabel terikatnya yaitu komunikasi interpersonal. Adapun hasil penelitian dari analisa data dirangkum dalam tabel 2. 
Hidayah, Amelia \& Hermansah; kontribusi kecerdasan emosional......

Tabel 2. Besar Hubungan dan Kontribusi Kecerdasan Emosional terhadap Komunikasi Interpersonal
Variabel
Besar Hubungan
Kategori
Kontribusi

$\begin{array}{llll}X \text { dengan } \boldsymbol{Y} & 0,544 & \text { Cukup Kuat } & 29,57 \%\end{array}$

Berdasarkan hasil analisa data dan perhitungan korelasi antara kecerdasan emosional dengan komunikasi interpersonal, diperoleh hasil yang menyatakan bahwa terdapat hubungan positif yang signifikan antara kecerdasan emosional dengan komunikasi interpersonal dalam pembelajaran matematika siswa kelas VII SMP Negeri 26 Batam. Besar hubungan termasuk kategori cukup kuat, artinya antara kecerdasan emosional dengan komunikasi interpersonal dalam pembelajaran matematika siswa terdapat hubungan yang cukup kuat. Hal ini berarti semakin baik kecerdasan emosional yang dimiliki siswa maka akan semakin baik atau semakin tinggi komunikasi interpersonal yang diperolehnya. Demikian pula sebaliknya, semakin buruk kecerdasan emosional yang dimiliki siswa maka akan semakin rendah pula komunikasi interpersonal yang diperolehnya.

Sesuai dengan kecerdasan pribadi (Goleman, 2016) yang ditempatkan oleh Salovey dalam definisi dasar tentang kecerdasan emosional yang dicetuskannya, seraya memperluas kemampuan ini menjadi lima wilayah utama: 1) Mengenali Emosi Diri. Kesadaran diri, mengenali perasaan sewaktu perasaan itu terjadi merupakan dasar kecerdasan emosional. Kemampuan memantau perasaan dari waktu ke waktu merupakan hal penting bagi wawasan psikologi dan pemahaman diri. Ketidakmampuan mencermati perasaan yang sesungguhnya membuat seseorang berada dalam kekuasaan perasaan. 2) Mengelola Emosi. Menangani perasaan agar perasaan dapat terungkap dengan pas adalah kecakapan yang bergantung pada pengendalian emosi. Orang-orang yang buruk dalam keterampilan ini akan terus-menerus bertarung melawan perasaan murung, sementara mereka yang pintar dapat bangkit kembali dengan jauh lebih cepat dari kemerosotan dan kejatuhan dalam kehidupan. 3) memotivasi diri sendiri. Menata emosi sebagai alat untuk mencapai tujuan adalah hal yang sangat penting dalam kaitan untuk memberi perhatian, untuk memotivasi diri sendiri dan menguasai diri sendiri, dan untuk berkreasi. Kendali diri emosional, menahan diri terhadap kepuasan dan mengendalikan dorongan hati adalah landasan keberhasilan dalam berbagai bidang. Dan, mampu menyesuaikan diri dalam "flow" memungkinkan terwujudnya kinerja yang tinggi dalam segala bidang. Orang-orang yang memiliki keterampilan ini cenderung lebih produktif dan efektif dalam hal apa pun yang mereka kerjakan. 4) Mengenali emosi orang lain. Empati, kemampuan yang juga bergantung pada kesadaran diri emosional, merupakan "keterampilan bergaul" dasar. Orang yang empati lebih mampu menangkap sinyalsinyal sosial yang tersembunyi yang mengisyaratkan apa-apa yang dibutuhkan atau dikehendaki orang lain. 5) Membina hubungan. Seni. Membina hubungan, sebagian besar merupakan keterampilan mengelola emosi orang lain. Ini merupakan keterampilan yang menunjang popularitas, kepemimpinan, dan keberhasilan antarpribadi. 
Jadi setiap aspek tersebut perlu dijalankan dan diseimbangkan agar kecerdasan emosional yang dimiliki siswa semakin baik. Jika siswa tidak dapat menjalankan atau menyeimbangkan antara kelima aspek, maka kecerdasan emosional yang dimilikinya kurang baik atau buruk. Sehingga akan mempengaruhi tidak tercapainya komunikasi interpersonal yang baik dalam pembelajaran matematika. Karena rendahnya kecerdasan emosional akan memperburuk emosi siswa yang tentunya mempengaruhi komunikasi interpersonal siswa dalam pembelajaran matematika. Dengan demikian dapat disimpulkan, bahwa hipotesis yang menyatakan terdapat hubungan positif yang signifikan antara kecerdasan emosional dengan komunikasi interpersonal dalam pembelajaran matematika siswa kelas VII SMP Negeri 26 Batam dengan kontribusi sebesar $29,57 \%$ diterima.

\section{Kesimpulan}

Berdasarkan hasil penelitian yang telah dilakukan, maka peneliti dapat menarik kesimpulan, yaitu sebagai berikut:

1. Terdapat hubungan positif yang signifikan antara kecerdasan emosional terhadap komunikasi interpersonal dalam pembelajaran matematika siswa kelas VII SMP Negeri 26 Batam dengan besar hubungannya $r_{x y}=0,544$ yang tergolong cukup kuat.

2. Terdapat kontribusi antara kecerdasan emosional terhadap komunikasi interpersonal dalam pembelajaran matematika siswa kelas VII SMP Negeri 26 Batam sebesar 29,57\%. Sedangkan sisanya sebesar 70,43\% dipengaruhi oleh faktor-faktor lain diluar penelitian ini.

\section{Daftar Pustaka}

Edward, D. (2015). Efektifitas komunikasi antarpribadi dan motivasi belajar siswa. Universitas Sumatera Utara.

Goleman, D. (2016). Emotional intelligence: kecerdasan emosional mengapa EI lebih penting daripada IQ. Jakarta: Gramedia.

Nggermanto, A. (2015). Kecerdasan quantum: melejitkan IQ, EQ, dan SQ. Bandung: Nuansa Cendikia.

Rakhmat, J. (2011). Psikologi komunikasi. Bandung: Remaja Rosdakarya.

Riduwan; \& Sunarto. (2011). Pengantar statistika untuk penelitian: pendidikan, sosial, komunikasi, ekonomi, dan bisnis. Bandung: Alfabeta.

Siregar, S. (2015). Statistik parametric untuk penelitian kuantitatif: dilengkapi dengan perhitungan manual dan aplikasi SPSS versi 17. Jakarta: Bumi Aksara.

Suciati. (2015). Psikologi komunikasi. Yogyakarta: Buku Litera. 